\title{
A spatial analysis of health-related resources in three diverse metropolitan areas
}

\author{
Melissa J. Smiley a,*, Ana V. Diez Roux ${ }^{\mathrm{a}}$, Shannon J. Brines ${ }^{\mathrm{b}}$, Daniel G. Brown ${ }^{\mathrm{b}}$, \\ Kelly R. Evenson ${ }^{c}$, Daniel A. Rodriguez ${ }^{\mathrm{d}}$ \\ ${ }^{a}$ Center for Social Epidemiology and Population Health, School of Public Health, University of Michigan, 109 Observatory Street, 3rd Floor, Ann Arbor, MI 48109-2029, USA \\ ${ }^{\mathrm{b}}$ School of Natural Resources and the Environment, University of Michigan, 440 Church Street, Ann Arbor, MI 48109-1041, USA \\ c Department of Epidemiology, Gillings School of Global Public Health, University of North Carolina at Chapel Hill, 137 E Franklin Street, Suite 306, Chapel Hill, NC 27514, USA \\ ${ }^{\mathrm{d}}$ Department of City and Regional Planning, University of North Carolina at Chapel Hill, New East Building, Chapel Hill, NC 27599-3140, USA
}

\section{A R T I C L E I N F O}

\section{Article history:}

Received 18 November 2009

Received in revised form

8 April 2010

Accepted 23 April 2010

\section{Keywords:}

Built environment

Spatial analysis

Race disparities

Neighborhoods

Supermarkets

Recreational facilities

\begin{abstract}
A B S T R A C T
Few studies have investigated the spatial clustering of multiple health-related resources. We constructed 0.5 mile kernel densities of resources for census areas in New York City, NY $(n=819$ block groups), Baltimore, MD $(n=737)$, and Winston-Salem, NC $(n=169)$. Three of the four resource densities (supermarkets/produce stores, retail areas, and recreational facilities) tended to be correlated with each other, whereas park density was less consistently and sometimes negatively correlated with others. Blacks were more likely to live in block groups with multiple low resource densities. Spatial regression models showed that block groups with higher proportions of black residents tended to have lower supermarket/produce, retail, and recreational facility densities, although these associations did not always achieve statistical significance. A measure that combined local and neighboring block group racial composition was often a stronger predictor of resources than the local measure alone. Overall, our results from three diverse U.S. cities show that health-related resources are not randomly distributed across space and that disadvantage in multiple domains often clusters with residential racial patterning. (c) 2010 Elsevier Ltd. All rights reserved.
\end{abstract}

\section{Introduction}

A growing body of public health research examines how health-related behaviors, such as diet and physical activity, are associated with features of the built environments in which people live, work, and play (Berrigan and Troiano, 2002; Brownson et al., 2005; French et al., 2001; Stafford et al., 2007). Specific health-related environmental features that are commonly investigated include the presence of supermarkets (Moore and Diez Roux, 2006; Zenk et al., 2005), parks and recreational facilities (Diez Roux et al., 2007), and features related to the walkability of the environment, such as the presence of nearby destinations, connectedness of streets, and a mix of different land uses (Saelens and Handy, 2008; Saelens et al., 2003). Studies have also shown that these types of features are spatially related to sociodemographic characteristics of the area, such as race and ethnicity. Previous research has found that areas with larger minority populations have stores with poorer quality produce (Zenk et al., 2006), low or no access to stores that sell healthy food (Moore and Diez Roux, 2006; Zenk et al., 2005; Galvez et al., 2008;

\footnotetext{
* Corresponding author. Tel.: +1 734615 9209; fax: +1 7347635706

E-mail address: mjsmiley@umich.edu (M.J. Smiley).
}

Morland and Filomena, 2007; Morland et al., 2002; Baker et al., 2006; Powell et al., 2007), disproportionately higher access to fast food restaurants (Kwate, 2008; Burns and Inglis, 2007), and fewer recreational facilities (Moore et al., 2008; Gordon-Larsen et al., 2006; Powell et al., 2006). This spatial inequality in health-related resources could be a contributing factor to racial and ethnic inequalities in health outcomes.

Parallel to this public health research, a body of research in urban planning examines patterning of area-level factors that are related to individual economic success. Historic residential racial segregation, along with a spatial distribution of jobs, affordable housing, and public transportation networks, greatly affects the ability of people to find and keep employment and housing. The spatial patterning of these types of factors creates a "geography of opportunity," such that individual economic success is associated with exposure to local opportunities (De Souza Briggs, 2005; Rosenbaumet al., 2002).

We hypothesize that just as the spatial clustering of jobs and housing define the geography of opportunity, the spatial clustering of health-related resources creates a "geography of health opportunity." In low health opportunity areas, the lack of multiple health-related features may have synergistic effects on health outcomes. Moreover, residents of these areas may be more likely to have individual-level disadvantages, creating the 
potential for even greater combined health effects. Understanding the geographic distribution and predictors of health opportunities, as well as their health consequences, could inform policy interventions.

To our knowledge, the collective spatial clustering of healthrelated resources and its association with area-level race/ ethnicity have not been examined in U.S. settings. Previous research has examined these health-related resources separately (Moore and Diez Roux, 2006; Zenk et al., 2006; Moore et al., 2008) or in other countries (Pearce et al., 2006; Witten et al., 2003). We focused on multiple resources that have been linked to healthrelated behaviors: supermarkets and produce stores, parks and recreational facilities, and retail areas as walking destinations. Using data collected from three diverse American cities, we examined the spatial clustering of these resources in each city. In addition, in order to study how residential segregation was associated with the clustering of resources and health opportunities, we also investigated associations of health opportunities with the race/ethnic composition of the local and the surrounding areas.

\section{Methods}

Three sites from the Multi-Ethnic Study of Atherosclerosis (MESA) Neighborhood Study are the focus of this analysisBaltimore, MD ( 737 block groups in the metropolitan area); New York City, NY (819 block groups in Northern Manhattan and the Bronx); and Winston-Salem, NC (169 block groups in the metropolitan area). These analyses examined race/ethnic data from the 2000 US Census and densities of four health-related resources, the locations of which were collected for the MESA Neighborhood Study: (1) supermarkets/produce stores; (2) recreational facilities; (3) parks; and (4) retail areas. These resources were selected because they commonly appear in the literature and have been linked to healthy behaviors. The number of block groups analyzed at each site was the contiguous area for which we could obtain locations of health-related resources, after accounting for the 0.5 mile buffer described below.

Information on locations and types of food stores was purchased in 2003 from InfoUSA (Papillion, Nebraska), a proprietary information service. Supermarkets were identified by selecting stores with recognizable chain name or more than 50 employees from all stores with standard industrial classification (SIC) codes 541101 and 541104-541106. Produce markets were defined by SIC codes (543101-543103, 549933). This analysis considered these two store types as a single type of resource likely to offer a variety of healthy foods. The decision to examine supermarkets and produce markets is supported by previous research suggesting a link between the presence of these types of stores and healthy dietary practices (Moore et al., 2008).

Recreational facility and park data were collected between April 2003 and June 2004 using a combination of online searches, phone calls verifying and collecting resources, and reviewing information published by planning and park authorities. The data included street address, whether the facility was publicly accessible, and if a fee was associated with use. The type and quantity of physical activities available were also collected, with a total of 48 types of unique activities identified (Diez Roux et al., 2007). Though these data were collected together, recreational facilities and parks are hypothesized to be patterned differently in space and are therefore treated as separate resources in this analysis.

The final health-related resource examined was retail area, which has been shown to be associated with walking trips (Rodriguez et al., 2009). Retail areas were identified from parcel-based land use and zoning data acquired from local planning authorities. The level of detail across sites varied greatly, as zoning codes in some sites broke down the general category of "retail" into numerous smaller categories. For this analysis, we collapsed categories of retail into a single general category that is comparable across all three sites. Because the distinction between current and planned land use was not always clear, all parcels zoned for retail use were considered retail.

Densities of all four health-related resources were estimated with a fixed kernel smoothing method, allowing for measurement of continuous resource densities over the entire area of each site (Gatrell et al., 1996). Kernel estimation gives more weight to resources that are near to each focal location, while allowing all resources within a given radius to exert some influence. We estimated resource densities within 0.5 miles of all $100 \mathrm{~m} \times 100$ $\mathrm{m}$ grid cells inside the study areas. Cell-level densities were averaged to the block-group level to obtain a summary measure of density for each block group. This approach of averaging densities for all cells over a given geographic area to provide an estimate of geographic accessibility of resources for definable spatial units has been previously used (Guagliardo, 2004).

These densities are not limited by block group boundaries, but instead reflect the range of resources reachable beyond the boundaries. In order to avoid boundary problems, we analyzed only block groups for which we had data coverage for at least 0.5 miles beyond their boundaries. We chose a 0.5 mile radius because it is small enough to limit the analysis to resources within a reasonable walking distance and large enough to likely include a selection of resources in each of our widely varied sites. We used straight-line distance, instead of network distance, because the quality of road network data (necessary to calculate network distances) varied by site and would have limited site comparisons.

Because population density affects resource density, we analyzed both raw densities of resources per square mile and "population-density-adjusted" densities of resources per 10,000 people. To adjust for population density, we divided the raw resource density kernel by a separate population density kernel and averaged the cell scores to the block-group level. Additionally, park and recreational facility densities were weighted by the number of activities available, such that parks or facilities with more activities were weighted higher. In the case of parks, activities available were assumed to be spread out evenly over space.

\subsection{Statistical analyses}

All analyses were site-specific. We calculated resource counts and block-group level densities (raw and population-densityadjusted). We quantified spatial clustering of resource densities with the Pearson correlation coefficients, after transforming mean densities into standard deviation units. We quantified spatial autocorrelation of block-group level densities with the Moran's I statistic. This statistic was calculated on raw resource densities and on residuals from univariate standard regression models with resource densities as a function of area-level race/ethnicity. For these Moran's I calculations and all subsequent spatial regression models, we employed a queen's first-order weight matrix, which treats all block groups that share a border as neighbors.

We examined the association of resources with area race/ ethnicity in two ways. Each block group was classified according to whether it was in the lowest site-specific quartile (low resource density) for zero, one, or two or more resource densities. We then calculated the percentage of people of each race/ethnicity who live in block groups with low access to zero, one, or two or more resources. These analyses included only three resources 
(supermarkets/produce stores, recreational facility activities, and retail areas) because the park activity density was not strongly correlated with the other resources. A separate category for the Hispanic people was not analyzed in sites other than New York City because of the small Hispanic population in those sites.

Second, we examined associations of area race/ethnic composition with resource densities with traditional and spatial regression models using the GeoDa (Anselin et al., 2006). Two types of spatial regression models (spatial lag and spatial error) were used in the analysis because of high spatial autocorrelation in the residuals of the standard models. In the spatial lag model, the outcome is modeled as a function of the independent variable $\left(x_{i}\right)$ and weighted neighboring values of the dependent variable $\left(\rho w_{i} y_{i}\right)$.

$y_{i}=\beta_{0}+\beta_{1} x_{i}+\rho w_{i} y_{i}+\varepsilon_{i}$

In this analysis, block-group level resource densities were modeled as a function of block-group race and densities of healthrelated resources in neighboring block groups. The dependent variable $\left(y_{i}\right)$ was either a single resource density or a combination of multiple resource densities. The independent variable $\left(x_{i}\right)$ was block group percent black (and additionally percent Hispanic in New York City). The $\beta_{1}$ coefficient was interpreted as the association of race/ethnic composition with resource density after controlling for neighboring block-group resource density. Rho $(\rho)$ captures the association of neighboring and local block-group resource access and therefore accounts for the spatial autocorrelation in the independent variable. The use of an interpretable spatial lag term $(\rho)$ treats spatial autocorrelation as a phenomenon of interest. Significantly positive spatial lag terms indicate that local areas with high dependent variable values have neighbors with high dependent variable values.

In the spatial error model, spatial autocorrelation is treated as a confounder rather than a phenomenon of interest. The model has separate error terms for the spatial uncorrelated errors $\left(\varepsilon_{i}\right)$ and for spatially correlated errors $\left(\lambda w_{i} \xi_{i}\right)$. The parameter $\lambda$ describes the extent to which the errors are correlated with each other, given the weighting scheme $w_{i}$. The beta coefficients are interpreted the same way.

$y_{i}=\beta_{0}+\beta_{1} x_{i}+\lambda w_{i} \xi_{i}+\varepsilon_{i}$

We contrasted both spatial models because both have some theoretical justification in our research problem. It is reasonable to expect that some portion of resource density is a function of neighboring area characteristics, suggesting that the spatial lag model that incorporates surrounding block-group densities as a predictor would appropriately capture the key underlying spatial processes. But it is also true that some of the spatial autocorrelation was introduced by calculation of the kernel densities themselves, suggesting a spatial error model to treat autocorrelation as a nuisance. Since the impact of surrounding areas on the local area is of scientific interest, but it is also partially due to spatial dependencies introduced by our methods; we report results from both types of spatial regression models.

The contextual effects of local block-group race/ethnicity and neighboring block-group race/ethnicity were calculated using different independent variables in two sets of models. In the first set of models, the independent variable was local-area (i.e., block group) percent black (in New York City we also included percent Hispanic). In the second set of models, the independent variable was the average of the local block group racial composition and the racial composition of neighboring block groups (those sharing a border with the local black-group). High correlations between local and surrounding block-group race/ethnicity precluded including them as separate covariates in the same model, hence the weighted average was used as a single term. Comparison of the local-area versus local and neighborhood averaged models allowed us to assess the importance of features of both local and surrounding areas in shaping health opportunity patterns.

After modeling the association of race/ethnicity with each individual resource, we combined three individual resource densities (supermarkets/produce stores, recreational facility activities, and retail areas) as a measure of health opportunity and modeled it as a function of area race/ethnicity. In the absence of empirical data on the relative importance of each resource for health, we opted to scale each resource density score to the same 1-100 range and combine them with equal weighting.

\section{Results}

Table 1 shows selected characteristics by site. New York City was the smallest site by land area, but the largest site by population. New York City had more health-related resources than the other sites except for retail area, which was more plentiful in Baltimore. As a result of high resource counts and small area, raw resource densities per square mile were highest in the New York City. For example, there were 9.9 supermarkets/ produce markets per square mile in New York City, compared to 1.0 in Baltimore and 0.3 in Winston-Salem. New York City had $383100 \mathrm{~m}^{2}$ retail areas per square mile, compared to 25.0 in Baltimore and 1.0 in Winston-Salem. There were 26.9 recreational facility activities per square mile in New York City, compared to 3.3 in Baltimore and 3.2 in Winston-Salem. Similarly, there were 31.6 park activities per square mile in New York City, compared to 5.1 in Baltimore and 3.3 in Winston-Salem.

After adjustment for population density, Winston-Salem had more supermarkets/produce markets (51.1 per 10,000 people), retail areas (200), recreational facilities (455), and park activities (435) than New York City or Baltimore. Baltimore consistently had the fewest resources per 10,000 people. Because availability of resources is often correlated with population density, and because

Table 1

Selected area and resource characteristics by site.

Baltimore Winston-Salem New York City

\begin{tabular}{|c|c|c|c|}
\hline \multicolumn{4}{|l|}{ Demographics } \\
\hline Area in square miles & 158.3 & 208.5 & 16.4 \\
\hline Block groups & 737 & 169 & 815 \\
\hline Population & 818,501 & 245,028 & $1,405,255$ \\
\hline Black & $53.1 \%$ & $29.2 \%$ & $24.0 \%$ \\
\hline Hispanic & $1.9 \%$ & $7.2 \%$ & $45.5 \%$ \\
\hline \multicolumn{4}{|l|}{ Counts $^{\mathrm{a}}$} \\
\hline Supermarkets & 69 & 35 & 73 \\
\hline Produce stores & 17 & 4 & 80 \\
\hline Retail area in square miles & 18.9 & 0.7 & 1.1 \\
\hline Recreational facilities & 142 & 98 & 152 \\
\hline Parks & 132 & 67 & 119 \\
\hline \multicolumn{4}{|l|}{ Densities $^{\text {b }}$} \\
\hline Supermarkets/produce stores & $1.0 / 1.1$ & $0.3 / 51.1$ & $9.9 / 31.3$ \\
\hline Retail areas of $100 \mathrm{~m}^{2}$ & $25.0 / 61.6$ & $1.0 / 200$ & $383 / 1304$ \\
\hline Recreational facility activities & $3.3 / 7.4$ & $3.2 / 455$ & $26.9 / 84.3$ \\
\hline Park activities & $5.1 / 5.9$ & $3.3 / 435$ & $31.6 / 122$ \\
\hline Health opportunities ${ }^{c}$ & $5.0 / 8.7$ & $5.0 / 801$ & $20.4 / 65.5$ \\
\hline
\end{tabular}

a The counts include total resources located within the final set of block groups analyzed. The count of resources analyzed is slightly larger than the counts reported here, because the analysis is based on all resources within $1 / 2$ mile buffer of the analysis area.

${ }^{\mathrm{b}}$ Resource densities are based on kernels with 0.5 mile radius. Mean blockgroup densities are reported per square mile/per 10,000 people.

${ }^{c}$ Health opportunities were created by scaling and equally combining supermarkets/produce store, retail area, and recreational facility activity densities. 
there were no stark differences between regression models using unadjusted or adjusted resource densities, we report the results from models with population-density-adjusted resource densities.

The Pearson's correlation coefficients comparing populationdensity-adjusted resource densities were mostly positive across all three sites, though they ranged from -0.03 to 0.62 (Table 2). The highest correlation was observed for retail area and recreational facility activities in Baltimore $(r=0.62)$ and no correlation at all was observed for park activities and retail area in Baltimore $(r=0.00)$. Most correlations were statistically significant at the $p<0.01$ level, with the exception of park activity density, which was not significantly correlated with any other density except recreational facility activities in WinstonSalem. Because our interest was in spatial clustering of resources, and because park density appeared to have a very different spatial pattern from the other resources, parks were omitted from further analyses.

With the exception of supermarket/produce stores and retail densities in Winston-Salem, residuals from standard linear regression models revealed statistically significant spatial autocorrelation (Table 2). For all resources, spatial autocorrelation in the residuals was consistently highest in the New York City (Moran's $I$ range from 0.76 to 0.92 ), intermediate in Baltimore (0.06-0.32) and lowest in Winston-Salem (0.01-0.24). The highest spatial correlation was observed for retail areas in New York City (0.92) and the lowest was observed for retail areas in Winston-Salem (0.01).

In each site, more blacks than whites reside in block groups with two or three low resource densities (36\% vs $19 \%$ in Baltimore, $28 \%$ vs $23 \%$ in Winston-Salem, and $31 \%$ vs $12 \%$ in New York City). More whites, as compared to blacks, reside in block groups without any low resource densities (45\% vs $35 \%, 37 \%$ vs $30 \%$, and $58 \%$ vs $28 \%$ ). Hispanics in New York City showed similar patterns to blacks (Fig. 1).

The low Moran's I statistics for Baltimore and Winston-Salem spatial model residuals indicated that nearly all of the spatial autocorrelation in the resource densities were accounted for (Table 3). Results for spatial error and spatial lag models were generally similar. In Baltimore and Winston-Salem, higher local black population was associated with lower population-densityadjusted supermarket/produce store, retail area, and recreational facility activity densities. The differences were statistically significant only for retail areas (in spatial lag models mean difference of -57.3 retail areas per 10,000 people [ $95 \%$ confidence interval -87.0 and -27.6 ] for each $1 \%$ increase in black population), recreational facilities activities ( -13.3 per 10,000 people [ -21.4 and -5.2$])$, and the summary health opportunities score ( -9.6 per 10,000 people [ -14.3 and -5.0$]$ ) in Baltimore and supermarkets/produce stores ( -55.4 per 10,000 people [ -104 and -6.5$]$ ) and health opportunities ( -633 per 10,000 people [ -1221 and -46.3$]$ ) in Winston-Salem. Spatial lag terms were statistically significant in all models except supermarkets/ produce store density in Winston-Salem (in the spatial lag model). For all model types and health resources, except recreational facility activity density in Winston-Salem, associations were stronger when we modeled the average of the local and neighboring area race/ethnicity as the independent variable, as compared to models with only local race/ethnicity. The statistical significance did not change.

In contrast to Baltimore and Winston-Salem models, the relatively high Moran's I statistics in the New York City models suggest residual spatial autocorrelation; so results must be interpreted with caution (Table 4). In the spatial lag models, larger percent black population at the block-group level was generally associated with lower resource densities, although the relationship was only statistically significant for supermarkets/produce stores ( -3.0 stores per 10,000 people $[-4.9,-1.1]$ in spatial lag model). The spatial error model showed associations in a similar direction with the exception of recreational facility activities, which were positively rather than negatively associated with percent black, although confidence intervals for both model types were wide. In general, inverse associations were stronger for the spatial error models than the spatial lag models. The relationship between Hispanic population and resource density was less clear. In the spatial lag models, recreational facility activity density was inversely associated with local percent Hispanic ( -8.6 per 10,000 people $[-14.0,-3.2])$ and local/surrounding percent Hispanic $(-10.2[-16.1,-4.2])$, but no associations were observed in the corresponding

Table 2

The Pearson correlations between block group population-density-adjusted resource densities and spatial autocorrelation for each density by site.

\begin{tabular}{|c|c|c|c|c|}
\hline & \multicolumn{3}{|c|}{ Pearson's correlation coefficients ${ }^{a}$} & \multirow[t]{2}{*}{ Moran's $I^{\mathrm{b}}$} \\
\hline & Retail area & Rec facility activities & Park activities & \\
\hline \multicolumn{5}{|l|}{ Baltimore } \\
\hline Supermarket/produce store & $0.50^{* * *}$ & $0.09 *$ & -0.01 & $0.17^{* *}$ \\
\hline Retail area & - & $0.62^{* *}$ & -0.01 & $0.32^{* *}$ \\
\hline Recreational facility activities & - & - & 0.00 & $0.06^{* *}$ \\
\hline Park activities & - & - & - & $0.19^{* * *}$ \\
\hline \multicolumn{5}{|l|}{ Winston-Salem } \\
\hline Supermarket/produce store & $0.18^{*}$ & $0.20^{* *}$ & 0.01 & 0.08 \\
\hline Retail area & - & 0.13 & 0.04 & 0.01 \\
\hline Recreational facility activities & - & - & $0.55^{* * *}$ & $0.24^{* *}$ \\
\hline Park activities & - & - & - & $0.17^{* *}$ \\
\hline \multicolumn{5}{|l|}{ New York City } \\
\hline Supermarket/produce store & $0.26^{* *}$ & $0.45^{* *}$ & -0.03 & $0.83^{* *}$ \\
\hline Retail area & - & $0.26^{* *}$ & 0.01 & $0.92^{* *}$ \\
\hline Recreational facility activities & - & - & -0.03 & $0.81^{* *}$ \\
\hline Park activities & - & - & - & $0.76^{* *}$ \\
\hline
\end{tabular}




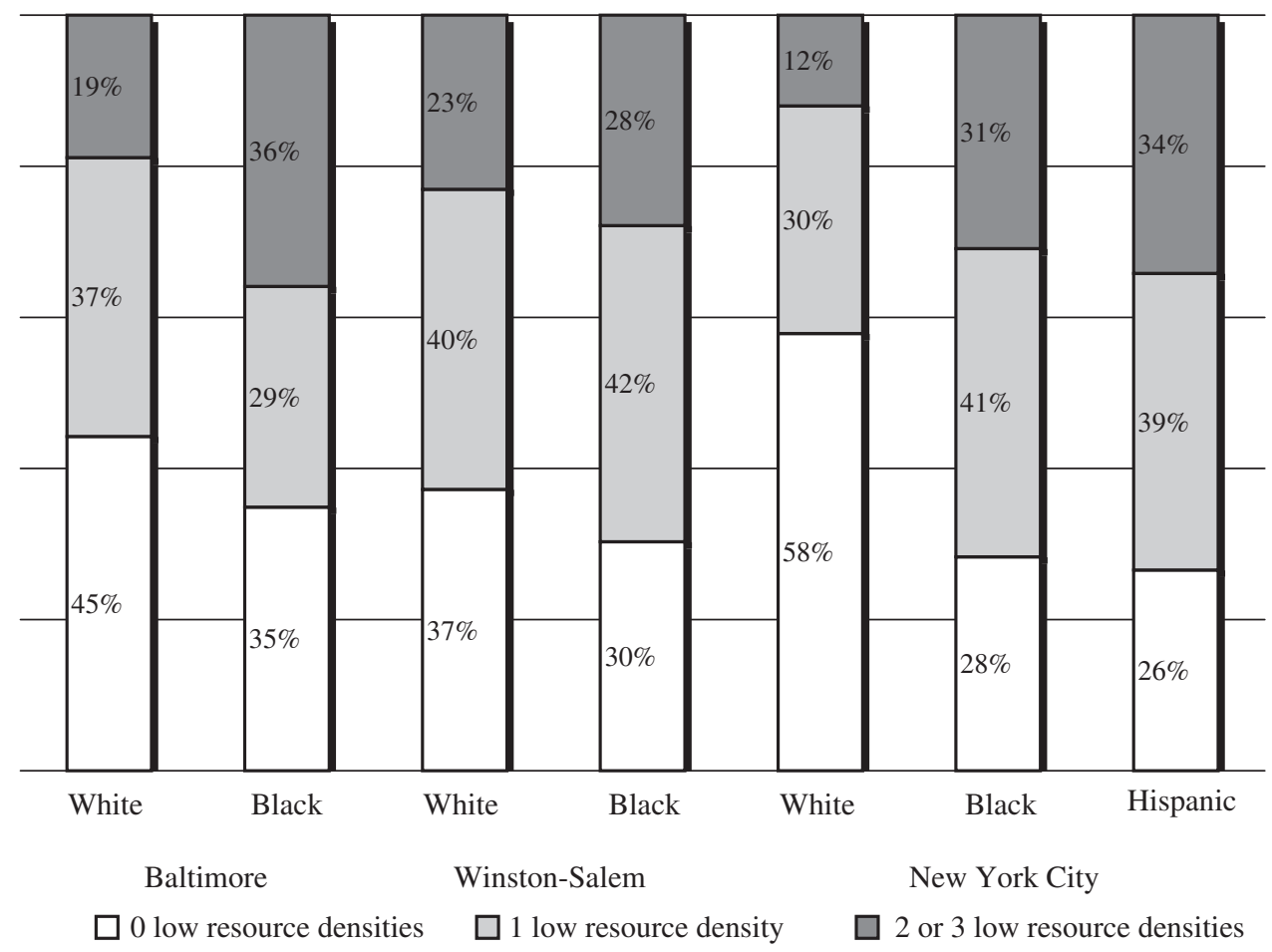

Fig. 1. Percent of residents by block-group level resource densities and by race/ethnicity.

Table 3

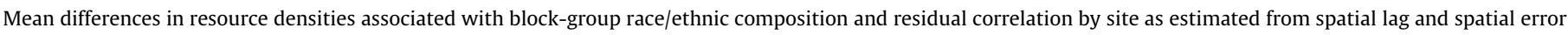
regression models: results for Baltimore and Winston-Salem.

\begin{tabular}{|c|c|c|c|c|c|c|c|}
\hline & \multirow[t]{2}{*}{ Spatial model type } & \multicolumn{3}{|l|}{ Local racial context ${ }^{\mathrm{a}}$} & \multicolumn{3}{|c|}{ Local+neighbor racial context ${ }^{b}$} \\
\hline & & \%Black [95\% CI] & $\rho^{\mathrm{c}}$ & Moran's $I^{\mathrm{d}}$ & \%Black [95\% CI] & $\rho^{\mathrm{c}}$ & Moran's $I^{\mathrm{d}}$ \\
\hline \multicolumn{8}{|l|}{ Baltimore } \\
\hline \multirow[t]{2}{*}{ Supermarkets and produce stores } & Lag & $-0.4[-0.9,0.1]$ & $0.4^{* * *}$ & 0.00 & $-0.5[-1.0,0.0]$ & $0.3^{* * *}$ & 0.00 \\
\hline & Error & $-0.5[-1.2,0.2]$ & na & 0.00 & $-0.7[-1.5,0.1]$ & na & 0.00 \\
\hline \multirow[t]{2}{*}{ Retail areas of $100 \mathrm{~m}^{2}$} & Lag & $-57.3[-87.0,-27.6]^{* * k}$ & $0.6^{* * *}$ & -0.01 & $-64.0[-96.0,-32.0]^{* *}$ & $0.6^{* *}$ & -0.01 \\
\hline & Error & $-90.3[-143,-37.2]^{* * *}$ & na & -0.01 & $-124[-187,-61.9]^{* k}$ & na & 0.00 \\
\hline \multirow[t]{2}{*}{ Recreational facility activities } & Lag & $-13.3[-21.4,-5.2]^{*}$ & $0.2^{*}$ & 0.00 & $-14.0[-22.6,-5.3]^{*}$ & $0.2^{*}$ & 0.00 \\
\hline & Error & $-15.6[-24.9,-6.2]^{*}$ & na & 0.00 & $-16.7[-26.7,-6.6]^{*}$ & na & 0.00 \\
\hline \multirow[t]{2}{*}{ Health opportunities } & Lag & $-9.6[-14.3,-5.0]^{* * *}$ & $0.4^{* * *}$ & 0.00 & $-10.8[-15.8,-5.7]^{* *}$ & $0.4^{* * *}$ & 0.00 \\
\hline & Error & $-13.2[-19.9,-6.6]^{* *}$ & na & 0.00 & $-16.1[-23.5,-8.8]^{* * *}$ & na & 0.00 \\
\hline \multicolumn{8}{|l|}{ Winston-Salem } \\
\hline \multirow[t]{2}{*}{ Supermarkets and produce stores } & Lag & $-55.4[-104,-6.5]^{*}$ & 0.2 & 0.00 & $-63.3[-119,-7.4]^{*}$ & 0.2 & 0.00 \\
\hline & Error & $-64.2[-120,-8.4]^{*}$ & na & 0.00 & $-76.2[-141,-11.2]^{*}$ & na & 0.00 \\
\hline \multirow[t]{2}{*}{ Retail areas of $100 \mathrm{~m}^{2}$} & Lag & $-133[-351,84.7]$ & 0.0 & 0.00 & $-172[-420,75.9]$ & 0.0 & 0.00 \\
\hline & Error & $-135[-354,83.8]$ & na & 0.00 & $-174[-421,73.4]$ & na & 0.00 \\
\hline \multirow[t]{2}{*}{ Recreational facility activities } & Lag & $-247[-707,212]$ & $0.6^{* * *}$ & 0.04 & $-243[-764,277]$ & $0.6^{* * *}$ & 0.04 \\
\hline & Error & $-455[-1200,291]$ & na & 0.04 & $-537[-1538,464]$ & na & 0.04 \\
\hline \multirow[t]{2}{*}{ Health opportunities } & Lag & $-633[-1221,-46.3]^{*}$ & $0.3^{*}$ & 0.01 & $-722[-1394,-49.5]^{*}$ & $0.3^{*}$ & 0.01 \\
\hline & Error & $-807[-1555,-58.7]^{*}$ & na & 0.01 & $-995[-1893,-96.6]^{*}$ & na & 0.01 \\
\hline
\end{tabular}

a Local racial context is modeled with local percent black as the independent variable.

b Local+neighbor racial context is modeled with an independent variable that incorporates local percent black and percent black in surrounding block groups.

c $\rho=$ The spatial lag term representing the association of the weighted average of race in neighboring block groups on the outcome.

d These Moran's I statistics are calculated in GeoDa without assessing statistical significance.

* $p$-Value of $<.05$

*** $p$-Value of $<.01$.

spatial error models. In the New York City, no consistent differences emerged when comparing models with only local race/ethnicity to those with local and neighboring race/ ethnicity.

\section{Discussion}

Overall, our results from three diverse U.S. cities show that health-related resources are not randomly distributed across 
Table 4

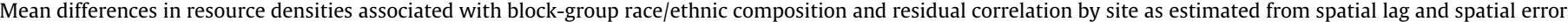
regression models: results for New York City.

\begin{tabular}{|c|c|c|c|c|c|c|c|c|c|}
\hline & \multirow{2}{*}{$\begin{array}{l}\text { Spatial } \\
\text { model } \\
\text { type }\end{array}$} & \multicolumn{4}{|l|}{ Local racial context ${ }^{\mathrm{a}}$} & \multicolumn{4}{|c|}{ Local+neighbor racial context ${ }^{b}$} \\
\hline & & $\begin{array}{l}\text { \%Black } \\
{[95 \% \mathrm{CI}]}\end{array}$ & $\begin{array}{l}\text { \%Hisp } \\
{[95 \% \mathrm{CI}]}\end{array}$ & $\rho^{\mathrm{c}}$ & Moran's $I^{\mathrm{d}}$ & $\begin{array}{l}\text { \%Black } \\
{[95 \% \mathrm{CI}]}\end{array}$ & $\begin{array}{l}\text { \%Hisp } \\
{[95 \% \mathrm{CI}]}\end{array}$ & $\rho^{\mathrm{c}}$ & Moran's $I^{\mathrm{d}}$ \\
\hline \multicolumn{10}{|l|}{ New York City } \\
\hline $\begin{array}{l}\text { Supermarkets and } \\
\text { produce stores }\end{array}$ & $\begin{array}{l}\text { Lag } \\
\text { Error }\end{array}$ & $\begin{array}{l}-3.0[-4.9,-1.1]^{* *} \\
-8.1[-14.2,-1.1]^{* *}\end{array}$ & $\begin{array}{l}-0.4[-2.0,1.1] \\
0.01[-5.1,5.1]\end{array}$ & $\begin{array}{l}1.0^{* * *} \\
\text { na }\end{array}$ & $\begin{array}{l}0.13 \\
0.12\end{array}$ & $\begin{array}{l}-2.8[-4.8,-0.7]^{* * *} \\
-26.7[-39.1,-14.3]^{* * *}\end{array}$ & $\begin{array}{l}-0.6[-2.3,1.0] \\
-3.9[-14.1,6.3]\end{array}$ & $\begin{array}{l}1.0^{* * *} \\
\text { na }\end{array}$ & $\begin{array}{l}0.13 \\
0.12\end{array}$ \\
\hline Retail areas of $100 \mathrm{~m}^{2}$ & $\begin{array}{l}\text { Lag } \\
\text { Error }\end{array}$ & $\begin{array}{l}-9.1[-54.1,35.9] \\
-109[-263,45.5]\end{array}$ & $\begin{array}{l}25.0[-14.4,64.4] \\
74.4[-54.4,203]\end{array}$ & $\begin{array}{l}1.0^{* * *} \\
\text { na }\end{array}$ & $\begin{array}{l}0.22 \\
0.21\end{array}$ & $\begin{array}{l}0.4[-47.1,47.9] \\
-306[-634,21.2]\end{array}$ & $\begin{array}{l}18.3[-23.3,59.9] \\
234[-33.1,502]\end{array}$ & $\begin{array}{l}1.0^{* * *} \\
\text { na }\end{array}$ & $\begin{array}{l}0.22 \\
0.21\end{array}$ \\
\hline $\begin{array}{l}\text { Recreational facility } \\
\text { activities }\end{array}$ & $\begin{array}{l}\text { Lag } \\
\text { Error }\end{array}$ & $\begin{array}{l}-1.8[-7.6,2.9] \\
6.8[-12.5,26.1]\end{array}$ & $\begin{array}{l}-8.6[-14.0,-3.2]^{* * *} \\
3.4[-12.7,19.6]\end{array}$ & $\begin{array}{l}1.0^{* * *} \\
\text { na }\end{array}$ & $\begin{array}{l}0.16 \\
0.15\end{array}$ & $\begin{array}{l}-2.0[-8.0,4.1] \\
12.5[-28.7,53.8]\end{array}$ & $\begin{array}{l}-10.2[-16.1,-4.2]^{* *} \\
-2.0[-35.7,31.7]\end{array}$ & $\begin{array}{l}1.0^{* * *} \\
\text { na }\end{array}$ & $\begin{array}{l}0.16 \\
0.15\end{array}$ \\
\hline Health Opportunities & $\begin{array}{l}\text { Lag } \\
\text { Error }\end{array}$ & $\begin{array}{l}-2.2[-4.6,0.3] \\
-6.0[-14.2,2.2]\end{array}$ & $\begin{array}{l}-0.5[-2.6,1.6] \\
4.3[-2.5,11.2]\end{array}$ & $\begin{array}{l}1.0^{* * *} \\
\text { na }\end{array}$ & $\begin{array}{l}0.17 \\
0.16\end{array}$ & $\begin{array}{l}-1.7[-4.3,0.9] \\
-21.8[-39.1,-4.5]^{*}\end{array}$ & $\begin{array}{l}-1.1[-3.3,1.1] \\
8.2[-5.9,22.4]\end{array}$ & $\begin{array}{l}1.0^{* *} \\
\text { na }\end{array}$ & $\begin{array}{l}0.17 \\
0.16\end{array}$ \\
\hline
\end{tabular}

${ }^{a}$ Local racial context is modeled with local percent black as the independent variable.

${ }^{\mathrm{b}}$ Local+neighbor racial context is modeled with an independent variable that incorporates local percent black and percent black in surrounding block groups.

c $\rho$ =The spatial lag term representing the association of the weighted average of race in neighboring block groups on the outcome.

d These Moran's I statistics are calculated in GeoDa without assessing statistical significance.

$* p$-Value of $<.05$.

** $p$-Value of $<.01$

space. There was evidence of significant spatial clustering of resources, although the strength of this clustering varied across sites and resources. Three of the four resource densities (supermarkets/produce stores, retail areas, and recreational facilities) tended to be correlated with each other, whereas park activity density was less consistently and sometimes negatively correlated with the others. There was also evidence of a spatial association between resources and area race/ethnic composition: in all three sites, blacks were more likely to live in block groups with multiple low resource densities. In Baltimore and Winston-Salem, spatial regression models showed that block groups with higher proportions of black residents tended to have lower supermarkets/produce, retail, and recreational facility densities, although these associations did not always achieve statistical significance. A measure that combined local and neighboring block group racial composition was a stronger predictor of resources than the local measure in these two sites. Results for New York City were generally consistent but more variable, possibly due to stronger spatial clustering of resources. In contrast to results for black residents, the percent of Hispanic residents was not consistently associated with resource density in the New York City.

The preponderance of research on health-related features of the built environment has found that single resource types such as supermarkets (Moore and Diez Roux, 2006; Zenk et al., 2006) or parks, and recreational facilities (Diez Roux et al., 2007; Moore et al., 2008; Abercrombie et al., 2008) are unequally distributed in space, with fewer resources found in minority neighborhoods. Our results showed clustering of three resources in space, resulting in important geographic differences in multiple resources simultaneously. Parks, however, did not follow the same pattern. This may be related to the historical evolution of residential segregation at the sites we studied, whereby both resource rich and resource poor areas are located adjacent to parks. It is important to note that we examined only park activity locations, not the quality of parks. It is plausible that park quality is patterned similarly to other resources, even if park location is not. Other research has suggested that park quality differs in low income and minority areas, even when park area does not (Smoyer-Tomic et al., 2004).
We found that more blacks and Hispanics live in areas with more low resource densities as compared to whites. The results from our regression models also showed that densities of supermarkets/produce stores, retail areas, and recreational facility activities were associated with area race/ethnicity, although the strength and significance of these associations varied by site. Overall, these results are consistent with other work investigating associations of race/ethnic composition with each of the resources individually (Moore and Diez Roux, 2006; Zenk et al., 2005; Zenk et al., 2006; Galvez et al., 2008; Morland and Filomena, 2007; Morland et al., 2002; Moore et al., 2008; Gordon-Larsen et al., 2006; Powell et al., 2006). We add to this work by showing that similar patterns are present for multiple resource measures, and that minority areas are more likely to be disadvantaged in multiple resources, as observed in Fig. 1. In addition, we also showed that these associations are not invariant, as illustrated by differences in the magnitude and direction of associations of resources with percent black and percent Hispanic in New York City.

We also investigated association with a summary measure of health opportunities. In each site, there was evidence that this summary score was often more strongly associated with race/ethnic composition than single resource scores. In both Baltimore and Winston-Salem, a greater percentage of black residents were consistently and significantly associated with a lower health opportunities score, even when individual resources were not. In addition, at all three sites, clear differences across areas emerged when disadvantage across multiple resources was considered. If multiple resources act synergistically to affect health, the clustering of multiple types of disadvantage in space could have important implications on health inequities. Future attempts at quantifying health opportunities should examine multiple resources and may need to examine different weighting schemes for combining resource densities. Ideally, these weights should be based on the relative importance of different types of resources for health.

This analysis also provides some evidence that a combination of local and neighboring area characteristics could be a better predictor of health-related resource densities than local characteristics alone. In nearly every model in each site, the magnitude of the association between race/ethnicity and resource 
access was stronger when the surrounding area was included. These results suggest that highly segregated areas (i.e., areas surrounded by other segregated areas) are most likely to lack resources. This finding suggests future research may need to consider the impact of more than just local contextual factors.

A strength of this analysis is the examination of the clustering of disadvantage in multiple resources. The use of kernel densities to characterize resource available allows a more flexible and realistic representation of proximity to resource (by giving some weight to resources located in a buffer around block group borders) than the calculation of simple densities for geographic units. Other researchers are utilizing similar methods and calling for further investigations into access to multiple resources (Pearce et al., 2006). An additional strength is the use of two types of spatial regression models to account for spatial dependencies in the data. Though we only report results from models with queen's first-order contiguity weights, we also ran models with three other weighting schemes and found no difference in the results. Spatial autocorrelation is a constant threat to the validity of spatial analyses and our use of kernel densities likely introduced additional spatial autocorrelation. The use of spatial regression models was appropriate in two sites, but residual spatial autocorrelation in the New York City suggests the scale of the relationships is finer than we can resolve with this analysis. Future analyses may benefit from the use of site-specific buffer sizes or adaptive kernel sizes that are small enough to capture spatial differences in built environments and flexible enough to reduce variance in the densities (Gatrell et al., 1996).

A limitation of this analysis is that we considered only resource location and not quality. Additionally, the use of retail zoning land-use data as a proxy for local walkable destinations may mean that we included undesirable or empty retail areas. We attempted to account for some variation in resource quality by including only large chain supermarkets and weighting recreational facilities and parks by number of activities on site, but additional steps could be taken in the future with richer datasets. An additional concern is that proximity to resources alone may be insufficient to affect healthy behaviors, and other factors such as crime/safety or other social attributes may be more relevant that resources or may interact with resources in shaping resource use as well as healthy behaviors. This analysis also treats all resources with equal importance. Some previous work has ranked resources according to their value for specifically defined populations(Witten et al., 2003) and future work should move in this direction as empirical data of the relative value of different types of resources for different populations or outcomes becomes available. Our health opportunities summary measure is therefore an important starting point but certainly not a complete or comprehensive measure of all local features potentially relevant to health.

Our sites were also not selected to be representative of the general population and future analyses should examine how resources cluster in other contexts and within geographic units other than block groups. In the absence of theory or empirical data linking a particular buffer size and health effects, we chose 0.5 mile buffers as a plausibly uniform walkable distance across three very different sites. Future refinements of our approach may include tailoring the buffer densities based on their importance to resource use and healthy behaviors. These analyses may also benefit from employing network rather than straight-line distances for constructing densities, as well as consideration of barriers to movement such as highways or bodies of water.

The absence of many health-related resources could have potentially synergistic effects on the residents of an area. Future work needs to more closely examine the clustering of these and other health-related resources, and then attempt to link these patterns to health behaviors and outcomes. These analyses may need to take into account the numerous other factors that may modify the impact of resources such as social environment features (e.g. crime rates, perception of safety, social cohesion, etc.) as well as cost and quality of resources.

Despite some limitations in the resource measures, our results clearly demonstrate that resources are not randomly distributed across space and that disadvantage in multiple resources cluster with local and surrounding area race/ethnic characteristics. These results highlight the importance of addressing these resource differences in order to reduce disparities in behaviors and other outcomes linked to resources.

\section{Funding}

This study was funded by R01 HL071759 from the National Institutes of Health $(\mathrm{NIH}) /$ National Heart, Lung, and Blood Institute (NHLBI). Funding was also provided by the Robert Wood Johnson Foundation through its national program Active Living Research. The content is solely the responsibility of the authors and does not necessarily represent the official views of the NIH.

\section{References}

Abercrombie, L.C., Sallis, J.F., Conway, T.L., Frank, L.D., Saelens, B.E., Chapman, J.E., 2008. Income and racial disparities in access to public parks and private recreation facilities. American Journal of Preventive Medicine 34 (1), 9-15.

Anselin, L., Syabri, I., Kho, Y., 2006. GeoDa: an introduction to spatial data analysis. Geographical Analysis 38 (1), 5.

Baker, E.A., Schootman, M., Barnidge, E., Kelly, C., 2006. The role of race and poverty in access to foods that enable individuals to adhere to dietary guidelines. Preventing chronic disease 3 (3), A76.

Berrigan, D., Troiano, R., 2002. The association between urban form and physical activity in U.S. adults. American Journal of Preventive Medicine 23 (2s), 74-79.

Brownson, R.C., Boehmer, T.K., Luke, D.A., 2005. Declining rates of physical activity in the United States: what are the contributors? Annual Review of Public Health 26 421-443.

Burns, C.M. \& Inglis, A.D. 2007, Measuring food access in Melbourne: access to healthy and fast foods by car, bus and foot in an urban municipality in Melbourne. Health \& Place.

De Souza Briggs, X. (Ed.), 2005. The Geography of Opportunity: Race and Housing Choice in Metropolitan America. Brookings Institution Press, Washington DC.

Diez Roux, A.V., Evenson, K.R., McGinn, A.P., Brown, D.G., Moore, L., Brines, S., Jacobs Jr, D.R., 2007. Availability of recreational resources and physical activity in adults. American Journal of Public Health 97 (3), 493-499.

French, S.A., Story, M., Jeffery, R.W., 2001. Environmental influences on eating and physical activity. Annual Review of Public Health 22, 309-335.

Galvez, M., Morland, K., Raines, C., Kobil, J., Siskind, J., Godbold, J., Brenner, B., 2008. Race and food store availability in an inner-city neighborhood. Public Health Nutrition 11, 624

Gatrell, A., Bailey, T., Diggle, P., Rowlingson, B., 1996. Spatial point pattern analysis and its application in geographical epidemiology. Transactions of the Institute of British Geographers 21, 256.

Gordon-Larsen, P., Nelson, M., Page, P., Popkin, B., 2006. Inequality in the built environment underlies key health disparities in physical activity and obesity. Pediatrics 117 (2), 417.

Guagliardo, M., 2004. Spatial accessibility of primary care: concepts, methods and challenges. International Journal of Health Geography 2 (1), 3.

Kwate, N., 2008. Fried chicken and fresh apples: racial segregation as a fundamental cause of fast food density in black neighborhoods. Health \& Place $14,32$.

Moore, L., Diez Roux, A., Evenson, K., McGinn, A., Brines, S., 2008. Availability of recreational resources in minority and low socioeconomic status areas. American Journal of Preventive Medicine 34 (1), 16.

Moore, L.V., Diez Roux, A.V., 2006. Associations of neighborhood characteristics with the location and type of food stores. American Journal of Public Health 96 (2), 325-331.

Moore, L.V., Diez Roux, A.V., Nettleton, J.A., Jacobs Jr, D.R., 2008. Associations of the local food environment with diet quality-a comparison of assessments based on surveys and geographic information systems: the multi-ethnic study of atherosclerosis. American Journal of Epidemiology 167 (8), 917-924.

Morland, K., Filomena, S., 2007. Disparities in the availability of fruits and vegetables between racially segregated urban neighborhoods. Public Health Nutrition 10 (12), 1481

Morland, K., Wing, S., Diez Roux, A., Poole, C., 2002. Neighborhood characteristics associated with the location of food stores and food service places. American Journal of Preventive Medicine 22 (1), 23-29. 
Pearce, J., Witten, K., Bartie, P., 2006. Neighbourhoods and health: a GIS approach to measuring community resource accessibility. Journal of epidemiology and community health 60 (5), 389-395.

Powell, L.M., Slater, S., Chaloupka, F.J., Harper, D., 2006. Availability of physical activityrelated facilities and neighborhood demographic and socioeconomic characteristics: a national study. American Journal of Public Health 96 (9), 1676-1680.

Powell, L.M., Slater, S., Mirtcheva, D., Bao, Y., Chaloupka, F.J., 2007. Food store availability and neighborhood characteristics in the United States. Preventive Medicine 44 (3), 189-195.

Rodriguez, D., Evenson, K.R., Diez-Roux, A., Brines, S., 2009. Land use, residential density, and walking: the Multi-Ethnic Study of Atherosclerosis. American Journal of Preventive Medicine 37 (5), 397-404.

Rosenbaum, J., Reynolds, L., Deluca, S., 2002. How do places matter? The geography of opportunity, self-efficacy, and a look inside the black box of residential mobility. Housing Studies 17 (1), 71-82.

Saelens, B.E., Sallis, J.F., Frank, L.D., 2003. Environmental correlates of walking and cycling: Findings from the transportation, urban design, and planning literatures. Annals of Behavioral Medicine 25 (2), 80-91.
Saelens, B.E., Handy, S.L., 2008. Built environment correlates of walking: A review. Medicine \& Science in Sports \& Exercise 40 (7,Supplement 1), S550-S566.

Smoyer-Tomic, K., Hewko, J., Hodgson, M., 2004. Spatial accessibility and equity of playgrounds in Edmonton, Canada. The Canadian Geographer 48 (3), 287.

Stafford, M., Cummins, S., Ellaway, A., Sacker, A., Wiggins, R.D., Macintyre, S., 2007. Pathways to obesity: identifying local, modifiable determinants of physical activity and diet. Social Science \& Medicine (1982) 65 (9) 1882-1897.

Witten, K., Exeter, D., Field, A., 2003. The quality of urban environments: mapping variation in access to community resources. Urban Studies 40 (1), 161-177.

Zenk, S., Schulz, A., Israel, B., James, S., Bao, S., Wilson, M., 2006. Fruit and vegetable access differs by community racial composition and socioeconomic position in Detroit, Michigan. Ethnicity \& Disease 16, 275

Zenk, S.N., Schulz, A.J., Israel, B.A., James, S.A., Bao, S., Wilson, M.L., 2005 Neighborhood racial composition, neighborhood poverty, and the spatial accessibility of supermarkets in metropolitan Detroit. American Journal of Public Health 95 (4), 660-667. 